\title{
Efeitos de ambiente e estimativas de parâmetros genéticos para características de carcaça em bovinos da raça Canchim criados em pastagem
}

\section{Sarah Laguna Meirelles ${ }^{1}$, Maurício Mello de Alencar$^{2}$, Henrique Nunes de Oliveira ${ }^{3}$, Luciana Correia de Almeida Regitano ${ }^{2}$}

\footnotetext{
1 Programa de Genética e Evolução - UFSCar - São Carlos, SP.

2 Embrapa Pecuária Sudeste - São Carlos. Bolsista do CNPq.

${ }^{3}$ Departamento de Zootecnia - FCAV - Unesp - Jaboticabal, SP.
}

RESUMO - Os objetivos neste trabalho foram estudar os efeitos de ambiente sobre a espessura de gordura subcutânea (EGS), a área de olho-de-lombo (AOL) e o peso aos 19 meses de idade e estimar parâmetros genéticos para essas características. Utilizaram-se informações obtidas de 987 bovinos da raça Canchim (5/8 Charolês + 3/8 Zebu) e do grupo genético animal MA (filhos de touros charoleses e vacas 1/2 Canchim + 1/2 Zebu) nascidos em 2003, 2004 e 2005. Os componentes de covariância foram estimados pelo método da máxima verossimilhança restrita utilizando-se um modelo animal com efeitos fixos (ano de nascimento, grupo genético, rebanho e sexo) e os efeitos aleatórios genético aditivo direto e residual. As médias de área de olho-de-lombo e peso foram mais altas nos machos que nas fêmeas. No grupo genético MA, as médias para todas as características foram mais altas que na raça Canchim e houve ainda efeitos de rebanho e de ano de nascimento. As estimativas de herdabilidade para $\operatorname{AOL}(0,33 \pm 0,09)$, EGS $(0,24 \pm 0,09)$ e peso $(0,23 \pm 0,09)$ foram moderadas, enquanto que a estimativa de correlação genética $(0,21 \pm 0,24)$ entre EGS e AOL foi baixa, o que sugere que essas características são controladas por diferentes conjuntos de genes de ação aditiva. As correlações genéticas para peso estimadas com EGS $(0,57 \pm 0,23)$ e com AOL $(0,62 \pm 0,16)$ foram moderadas. Conclui-se que as características ao sobreano devem responder à seleção nos rebanhos estudados e que a seleção para aumento de peso também eleva EGS e AOL e vice-versa.

Palavras-chave: área de olho-de-lombo, correlação genética, espessura de gordura, herdabilidade, peso

\section{Environmental effects and genetic parameters estimates for carcass traits in Canchim cattle raised on pastures}

ABSTRACT - The objective in this work was to study the effects of environmental factors on subcutaneous fat thickness (BFT), loin eye area (REA) and body weight (BW) measured at 19 months of age and to estimate genetic parametersfor these traits. It was used information obtained from 987 Canchim (5/8 Charolais + 3/8 Zebu) and MA genetic group (offspring of Charolais bulls and 1/2 Canchim $+1 / 2$ Zebu cows) bulls and heifers, born in 2003, 2004, and 2005. Covariance components were estimate by restricted likelihood method using animal model with fixed effects (year of birth, genetic group, herd, and sex) and residual and direct additive genetic random effects. Means of loin eye area and weight were higher for males than for females. In the MA genetic group, the means, for all traits, were higher than in the Canchim group, and there were still the effects of herd and year of birth. The heritability estimates of REA $(0.33 \pm 0.09)$, BFT $(0.24 \pm 0.09)$ and BW (0.23 \pm 0.09$)$ were moderate, while genetic correlation estimate $(0.21 \pm 0.24)$ between BFT and REA was low, suggesting that traits are controlled by different sets of genes with additive action. Genetic correlations of BW with BFT $(0.57 \pm 0.23)$ and REA $(0.62 \pm 0.16)$ are moderate. It is possible to conclude that those traits can respond for selection and they indicate that selection for BW will increase also enhance BFT and REA and vice versa.

Key Words: backfat thickness, body weight, genetic correlation, heritability, rib eye area

\section{Introdução}

Para manter-se como maior exportador de carne bovina, o Brasil precisa adequar sua produção aos padrões e às exigências estabelecidos pelos importadores. Um dos aspectos mais importantes a ser melhorado na pecuária bovina de corte do Brasil diz respeito às características determinantes da qualidade das carcaças

Entre as características de carcaça, a espessura de gordura subcutânea (EGS) tem grande importância no 
processamento da carne, sendo fundamental no processo de resfriamento da carcaça, funcionando como isolamento térmico. O resfriamento deve ser feito de forma lenta e gradual para não causar encurtamento das fibras e, consequentemente, endurecimento da carne. A ausência de gordura de cobertura permite perda excessiva de água, ocasionando, além da perda de peso, o escurecimento da carne durante o período de resfriamento. A consequência é a diminuição do peso dos cortes comerciais e a redução na qualidade da carne. Segundo Ferreira et al. (2006), os frigoríficos exigem que a carcaça tenha no mínimo $3,00 \mathrm{~mm}$ de espessura de gordura sobre a $12^{\mathrm{a}}$ costela.

Outra característica de carcaça importante é a área de olho-de-lombo (AOL), medida relacionada à musculosidade e usada como indicadora de rendimento dos cortes de alto valor comercial, apresentando correlação positiva com a porção comestível da carcaça (Luchiari Filho, 2000).

Portanto, considerando a melhoria da qualidade das carcaças bovinas como objetivo de seleção, essas duas características, EGS e AOL, podem ser incluídas como critérios de seleção nos programas de melhoramento genético de bovinos de corte do país. Para tanto, é necessário verificar os efeitos de fatores de meio que podem atuar sobre estas características e estimar parâmetros genéticos para elas, de modo que o progresso genético esperado possa ser calculado, fornecendo subsídio aos programas de avaliação genética para a tomada de decisões. Dessa maneira, os objetivos deste trabalho foram estudar os efeitos de ambiente que interferem na determinação da EGS e da AOL e estimar parâmetros genéticos para essas características e para o peso aos 18 meses de idade em uma população da raça Canchim.

\section{Material e Métodos}

As medidas de espessura de gordura subcutânea (EGS) e área de olho-de-lombo (AOL) foram obtidas em animais da raça Canchim e do grupo MA (filhos de touros Charoleses e vacas $1 / 2$ Canchim $+1 / 2$ Zebu), machos e fêmeas, com média de 19 meses de idade, criados em sete fazendas de dois estados do Brasil (SP e GO). Em 2005 e 2006, foram coletados dados em apenas duas fazendas e, em 2007, nas sete fazendas.

As medidas de EGS (mm) e de AOL $\left(\mathrm{cm}^{2}\right)$ foram coletadas transversalmente no músculo longissimus, na região entre a $12^{\underline{a}}$ e $13^{\underline{a}}$ costelas. Para a coleta das imagens, utilizou-se óleo vegetal no local da medição, para garantir o contato acústico entre a sonda linear e o corpo do animal. Nos anos de 2005 e 2006, as mensurações foram feitas utilizando um aparelho Piemedical Scanner 200 Vet com transdutor linear de $18 \mathrm{~cm}$ e 3,5 MHz, e as medidas foram obtidas no momento da tomada das imagens. Em 2007, utilizou-se um aparelho ALOKA 500V, com sonda linear de 17,2 cm e 3,5 MHz, e as medidas foram tomadas posteriormente por um software específico para análise de imagens. As medidas de ultrassom foram tomadas nos meses de março e abril de cada ano, quando os animais tinham de 16 a 22 meses de idade, conforme sugerido por Magnabosco et al. (2003); na mesma ocasião os animais também foram pesados.

Para avaliar a significância estatística dos efeitos ambientais e genéticos que atuam sobre as características de carcaça e o peso, foram realizadas análises de variância pela metodologia dos quadrados mínimos, utilizando um modelo estatístico que incluiu os efeitos de ano de nascimento, grupo genético (Canchim ou MA), rebanho e sexo do animal, além da covariável idade do animal por ocasião da medida.

Para obtenção dos componentes de (co)variância, foram realizadas análises uni e bicaracterísticas. Utilizou-se um modelo animal com os efeitos fixos de grupo de contemporâneos e da covariável idade do animal na data da medida (efeito linear), além dos efeitos aleatórios genéticos aditivos diretos e residuais. Nas análises unicaracterísticas de EGS e AOL, foram ajustados dois modelos, com e sem a covariável peso do animal. As análises foram realizadas pelo método da máxima verossimilhança restrita livre de derivadas, utilizando o programa computacional MTDFREML (Boldman et al., 1995). O grupo de contemporâneos (GC) foi formado pelas seguintes variáveis: ano de nascimento, rebanho, grupo genético e sexo. O número de animais na matriz de parentesco foi 3.946. Nas análises bicaracterísticas, foram consideradas somente as observações com registros das duas características (EGS e AOL), e o número mínimo de animais por GC foi sete. O modelo estatístico na forma matricial é descrito como:

$$
\mathrm{y}=\mathrm{X} \beta+\mathrm{Za}+\mathrm{e},
$$

em que: $\mathrm{y}=$ vetor das variáveis dependentes; $\beta=$ vetor de efeitos fixos (grupo de contemporâneos e covariável); a = vetor de efeitos genéticos aditivos diretos; e = vetor de erros aleatórios residuais associados às observações; e $\mathrm{X}$ e $\mathrm{Z}$ = respectivas matrizes de incidência para cada efeito.

Este modelo leva em conta as seguintes pressuposições:

$$
\mathrm{E}(\mathrm{y})=\mathrm{X} \beta, \mathrm{E}(\mathrm{a})=0 \text { e } \mathrm{E}(\mathrm{e})=0 \quad \operatorname{Var}\left[\begin{array}{l}
a \\
e
\end{array}\right]=\left[\begin{array}{ll}
G & 0 \\
0 & R
\end{array}\right]
$$

em que: $\mathrm{G}=\mathrm{A} \sigma_{\mathrm{a}}{ }^{2}$, matriz de variância genética aditiva; $\mathrm{A}=$ matriz de parentesco; $\mathrm{R}=\mathrm{I} \sigma_{\mathrm{e}}^{2}$, matriz de variância residual; $\mathrm{I}=$ matriz identidade; $\sigma_{\mathrm{a}}^{2}=$ variância genética aditiva direta; $\sigma_{\mathrm{e}}^{2}=$ variância residual. 


\section{Resultados e Discussão}

As médias de EGS e AOL observadas neste trabalho (Tabela 1) são semelhantes às relatadas por Yokoo et al. (2008), de 1,93 $\pm 1,36 \mathrm{mme} 48,38 \pm 8,72 \mathrm{~cm}^{2}$, respectivamente, em bovinos da raça Nelore criados em pastagem ou semiconfinados entre 15 e 19 meses, semelhantes às dos animais deste trabalho. Diversos autores observaram valores superiores aos do presente estudo para as médias de AOL e inferiores para EGS (Turner et al., 1990; Arnold et al., 1991; Moser et al., 1998; Kemp et al., 2002) para animais das raças Hereford, Brangus, Angus ou Santa Gertrudis, com idades entre 350 e 555 dias, que variaram de $47,46 \mathrm{~cm}^{2}$ a $86,00 \mathrm{~cm}^{2}$ e de 0,47 a $0,95 \mathrm{~mm}$, respectivamente.

O coeficiente de variação elevado (40,67 \%) para a característica EGS concorda com Meyer et al. (2004) (44,78 e $50,01 \%$ para touros e novilhas, respectivamente), que reportaram médias de 3,46 mm e 4,09 mm e desvios-padrão de 1,55 mm e 2,08 mm para a EGS para touros e novilhas da raça Hereford, respectivamente. Yokoo et al. $(2008,2009)$ reportaram coeficiente de variação também elevado para EGS $(70,46 \%)$ para animais da raça Nelore. Rubiano et al. (2009), trabalhando com animais da raça Canchim em sistema de confinamento, encontraram valores de $91,30 \mathrm{~cm}^{2}$ para
AOL e 5,00 mm para EGS, demonstrando que os animais desta raça respondem a estas características quando recebem suplementação.

Todos os efeitos incluídos nos modelos foram significativos $(\mathrm{P}<0,05$ ou $\mathrm{P}<0,01)$ para todas as características, com exceção de ano de nascimento para AOL e de sexo para EGS, em análises unicaracterísticas.

Conforme o esperado (Tabela 2), a AOL e o peso foram maiores nos machos do que nas fêmeas, uma vez que, segundo Lawrie (1991), os machos inteiros têm maior velocidade de desenvolvimento muscular em relação aos machos castrados e às fêmeas. Além disso, pelo fato de a AOL ter correlação alta com o peso (Moser et al., 1998; Stelzleni et al., 2002), esperava-se que os machos apresentassem maior AOL. Yokoo et al. (2007) também observaram maior AOL em machos do que em fêmeas para a raça Nelore. Hassen et al. (1998) verificaram, para produtos de cruzamentos, maior AOL nas carcaças de touros do que nas de novilhos, quando abatidos aos 15 meses de idade, após confinamento.

O sexo do animal não apresentou efeito significativo sobre a EGS (Tabela 2), ao contrário do que era esperado, uma vez que, segundo Luchiari Filho (2000), o sexo do animal influencia o crescimento dos tecidos da carcaça, com

Tabela 1 - Estrutura dos dados e estatísticas descritivas para as características estudadas em bovinos da raça Canchim

\begin{tabular}{|c|c|c|c|c|c|c|}
\hline Característica & $\begin{array}{c}\text { Grupos de } \\
\text { contemporâneos }\end{array}$ & $\begin{array}{c}\text { Animais } \\
\text { com medida }\end{array}$ & $\begin{array}{c}\text { Média } \pm \\
\text { desvio-padrão }\end{array}$ & $\begin{array}{c}\text { Coeficiente } \\
\text { de variação (\%) }\end{array}$ & Mínimo & Máximo \\
\hline Peso $(\mathrm{kg})$ & 32 & 950 & $323,26 \pm 59,00$ & 18,25 & 163 & 564 \\
\hline Espessura de gordura subcutânea (mm) & 32 & 987 & $1,90 \pm 0,77$ & 40,67 & 0,60 & 5,40 \\
\hline Idade na mensuração (dias) & 32 & 987 & $569,70 \pm 47,77$ & 8,38 & 467 & 681 \\
\hline
\end{tabular}

Tabela 2 - Características avaliadas de acordo com ano de nascimento, rebanho, sexo e grupo genético em bovinos da raça Canchim

\begin{tabular}{|c|c|c|c|c|c|}
\hline \multirow[t]{2}{*}{ Fonte de variação } & \multirow[t]{2}{*}{ Classe } & \multirow{2}{*}{$\begin{array}{c}\text { Número de } \\
\text { animais }\end{array}$} & \multicolumn{3}{|c|}{ Característica } \\
\hline & & & Área de olho-de-lombo $\left(\mathrm{cm}^{2}\right)$ & Espessura de gordura subcutânea (mm) & Peso (kg) \\
\hline \multirow[t]{3}{*}{ Ano de nascimento } & 2003 & 260 & $45,50 \pm 0,73$ & $1,73 \pm 0,05$ & $332,34 \pm 4,51$ \\
\hline & 2004 & 276 & $45,38 \pm 0,74$ & $1,80 \pm 0,05$ & $343,50 \pm 4,24$ \\
\hline & 2005 & 451 & $45,42 \pm 0,47$ & $2,68 \pm 0,03$ & $339,08 \pm 2,76$ \\
\hline \multirow[t]{7}{*}{ Rebanho } & 1 & 44 & $54,03 \pm 1,19$ & $2,24 \pm 0,09$ & $404,67 \pm 6,83$ \\
\hline & 2 & 28 & $45,73 \pm 1,48$ & $2,42 \pm 0,11$ & $339,71 \pm 8,65$ \\
\hline & 3 & 397 & $45,95 \pm 0,45$ & $1,77 \pm 0,03$ & $324,37 \pm 2,67$ \\
\hline & 4 & 387 & $50,11 \pm 0,38$ & $1,65 \pm 0,03$ & $336,31 \pm 2,35$ \\
\hline & 5 & 50 & $36,21 \pm 1,16$ & $1,88 \pm 0,08$ & $266,55 \pm 6,77$ \\
\hline & 6 & 50 & $43,02 \pm 1,21$ & $2,26 \pm 0,09$ & $344,17 \pm 6,98$ \\
\hline & 7 & 31 & $43,02 \pm 1,45$ & $2,28 \pm 0,10$ & $352,36 \pm 8,39$ \\
\hline \multirow[t]{2}{*}{ Sexo } & Machos & 455 & $48,31 \pm 0,62$ & $2,10 \pm 0,04$ & $366,05 \pm 3,65$ \\
\hline & Fêmeas & 532 & $42,57 \pm 0,57$ & $2,03 \pm 0,04$ & $310,57 \pm 3,31$ \\
\hline \multirow{2}{*}{$\begin{array}{l}\text { Grupo } \\
\text { genético }\end{array}$} & Canchim & 713 & $44,59 \pm 0,49$ & $2,02 \pm 0,03$ & $326,19 \pm 2,79$ \\
\hline & Grupo MA & 274 & $46,28 \pm 0,73$ & $2,12 \pm 0,05$ & $350,42 \pm 4,38$ \\
\hline
\end{tabular}

MA = animais filhos de touros Charoleses e vacas $1 / 2$ Canchim e $1 / 2$ Zebu. 
efeito mais pronunciado observado através do processo de engorda.

Ainda segundo o mesmo autor, a taxa de acúmulo de gordura nos machos inteiros é menor do que nos novilhos, que por sua vez é menor do que nas novilhas. Burrow et al. (1991), estudando animais produtos de cruzamento entre raças zebuínas, observaram que, de acordo com as curvas de crescimento alométrico, as fêmeas depositaram gordura mais precocemente que os machos castrados e inteiros. Neste trabalho a EGS foi a mesma para machos inteiros e para fêmeas, discordando dos resultados relatados por Yokoo et al. (2007), os quais verificaram maior espessura de gordura obtida por ultrassom em fêmeas em relação aos machos, para animais da raça Nelore. Para animais produtos de cruzamentos, Hassen et al. (1998) verificaram maior espessura de gordura na carcaça de novilhos, seguidos de novilhas e, por último, de touros, quando confinados após a desmama e abatidos por volta dos 15 meses de idade.

Em relação aos grupos genéticos (Tabela 2), foram observados maiores AOL, EGS e peso para os animais MA; estes possuem $65,62 \%$ dos genes oriundos da raça Charolesa, enquanto nos animais Canchim obtidos pelos outros sistemas de acasalamento, o máximo da raça Charolesa atingida é $64,84 \%$, o que pode ter contribuído para o melhor desenvolvimento dos animais MA. Além disso, estes possuem $68,75 \%$ de heterozigose, enquanto os da raça Canchim possuem menos de 50,00 \%, o que também pode ter contribuído para o melhor desempenho dos animais MA. Trematore et al. (1998) observaram efeito aditivo direto da raça Charolesa em relação à Nelore e efeito heterótico individual das raças Charolesa e Nelore positivos para o peso à desmama para animais criados em pastagens.

Quanto aos efeitos de rebanho, diferenças de manejo e mesmo genéticas podem ser responsáveis pelas diferenças de desempenho (Tabela 2). Yokoo et al. (2007) também verificaram efeito significativo de rebanho sobre AOL e EGS para animais da raça Nelore.

Os coeficientes de regressão linear observados neste estudoparaEGS $(0,0023 \pm 0,0004 \mathrm{~mm}), \mathrm{AOL}\left(0,030 \pm 0,005 \mathrm{~cm}^{2}\right)$ e peso $(0,37 \pm 0,03 \mathrm{~kg})$ sobre a idade do animal indicam que os animais mais velhos apresentaram maiores EGS, AOL e peso. Yokoo et al. (2007) verificaram efeitos linear e quadrático significativos de idade do animal sobre AOL e EGS em animais da raça Nelore. Neste trabalho, o efeito quadrático de idade não foi significativo para as três características estudadas e, portanto, foi retirado do modelo.

As estimativas de herdabilidade para as características estudadas foram moderadas, indicando que devem responder à seleção (Tabela 3).
Tabela 3 - Estimativas dos componentes de variância e parâmetros genéticos para características de carcaça e peso obtidas por análises unicaracterísticas para bovinos da raça Canchim

\begin{tabular}{lccc}
\hline Característica & \multicolumn{3}{c}{ Estimativa } \\
\cline { 2 - 4 } & ${ }^{1} \sigma_{\mathrm{a}}^{2}$ & ${ }^{2} \sigma_{\mathrm{e}}^{2}$ & ${ }^{3} \mathrm{~h}^{2}$ \\
\hline${ }^{4} \mathrm{EGS}$ & 0,065 & 0,210 & $0,24 \pm 0,09$ \\
${ }^{5} \mathrm{AOL}$ & 13,730 & 28,010 & $0,33 \pm 0,09$ \\
Peso & 290,980 & 983,740 & $0,23 \pm 0,09$ \\
\hline
\end{tabular}

${ }^{1} \sigma^{2}=$ variância genética aditiva; ${ }^{2} \sigma^{2}=$ variância residual; ${ }^{3} h^{2}=$ herdabilidade; ${ }^{4} \mathrm{EGS}=$ espessura de gordura subcutânea; ${ }^{5} \mathrm{AOL}$ = área de olho-de-lombo.

A estimativa de herdabilidade encontrada para EGS $(0,24)$ foi inferior às obtidas por Reverter et al. $(2000)$ e Kemp et al.(2002) para a raça Angus (0,51 e 0,39, respectivamente), e por Crews et al. (2003) para touros da raça Simental $(0,53)$, todos trabalhando com animais criados em regime de confinamento. Yokoo et al. (2008) e Lima Neto et al. (2009) também encontraram estimativas de herdabilidade para EGS superiores $(0,52$ para a raça Nelore e 0,10 para a raça Guzerá, respectivamente), mas com animais em regime de pastagem e semiconfinados. Por outro lado, Stelzleni et al. (2002), para a raça Brangus, estimaram o valor de herdabilidade de 0,26 para a EGS para animais confinados, bem próximo ao valor estimado neste trabalho $(0,24)$; Reverter et al. (2000) estimaram o valor de 0,18 , para a raça Hereford.

Valores semelhantes à estimativa de herdabilidade obtida neste trabalho para AOL $(0,33)$ foram reportados por diversos autores, tais como Moser et al. (1998) e Stelzleni et al. (2002), para a raça Brangus (0,29 e 0,31, respectivamente); Reverter et al. (2000), para a raça Hereford $(0,38)$; Kemp et al. (2002) e Davis et al. (2003), para a raça Angus (0,29 e 0,31, respectivamente); Crews et al. (2003), para a raça Simental (0,37); Yokoo et al. (2010), para a raça Nelore (0,35); e Lima Neto et al. (2009), para a raça Guzerá (0,34). Entretanto, Yokoo et al. (2010) estimaram valor maior $(0,43)$ do que o obtido neste trabalho para a raça Nelore, enquanto Reverter et al. (2000) estimaram o valor de 0,42 para animais da raça Angus.

A estimativa de herdabilidade obtida para peso na data do ultrassom $(0,23)$ foi inferior aos valores encontrados por Alencar et al. (1993) e por Mascioli et al. (1996), para a raça Canchim ao sobreano (0,41 e 0,54, respectivamente); por Yokoo et al. (2010), para a raça Nelore $(0,66)$; e por Lima Neto et al. (2009), para a raça Guzerá $(0,41)$.

Os erros padrão das estimativas de correlação genética entre as características analisadas foram altos devido ao número de animais envolvidos nas análises. A correlação genética entre EGS e AOL estimada neste trabalho é de 
baixa magnitude, sugerindo que as duas características são determinadas por diferentes conjuntos de genes de ação aditiva (Tabela 4). Outros trabalhos também reportaram baixas estimativas de correlação genética entre essas características: Stelzleni et al. (2002) estimaram o valor de -0,09 para animais da raça Brangus, e Yokoo et al. (2010) reportaram o valor de 0,06 para a raça Nelore. A estimativa de correlação genética obtida neste trabalho indica que a seleção para qualquer uma das duas características não deve resultar em mudanças na outra, ou seja, pode-se selecionar para aumentar uma e selecionar para reduzir a outra, ou para aumentar ou reduzir as duas.

As correlações genéticas estimadas entre o peso e as características de carcaça foram de magnitudes moderadas (Tabela 4), concordando com o estudo de Stelzleni et al. (2002), os quais estimaram os valores de 0,44 e 0,42 para as correlações de peso com AOL e com EGS, respectivamente. Essas estimativas indicam que a seleção para aumento de peso deve também resultar em aumentos na EGS e na AOL e vice-versa. A correlação genética estimada entre EGS e peso é maior que as reportadas em outros estudos, como os de Moser et al. (1998) e Yokoo et al. (2010), que obtiveram correlações genéticas iguais a 0,11 e 0,06 , respectivamente. No entanto, a correlação genética estimada entre AOL e peso foi semelhante à observada por Yokoo et al. (2010), de 0,64 .

Quando o peso foi incluído no modelo estatístico para as análises unicaracterísticas para EGS e AOL, as herdabilidades estimadas foram, respectivamente, iguais a $0,19 \pm 0,08$ e $0,29 \pm 0,10$, ligeiramente inferiores aos valores obtidos sem a inclusão dessa covariável, apesar das moderadas correlações genéticas do peso com a EGS e com a AOL.

Tabela 4 - Estimativas dos componentes de variância e parâmetros genéticos para características de carcaça e peso obtidas por análises bicaracterísticas para bovinos da raça Canchim

\begin{tabular}{|c|c|c|c|c|c|c|c|c|c|}
\hline \multirow[b]{2}{*}{ EGS } & \multirow[b]{2}{*}{ AOL } & \multicolumn{7}{|c|}{ Estimativa } & \multirow[b]{2}{*}{ Correlação residual } \\
\hline & & $\sigma_{\mathrm{a} 1}^{2}$ & $\sigma_{\mathrm{a} 2}^{2}$ & $\sigma_{\mathrm{a} 1 \mathrm{a} 2}$ & $\sigma_{\mathrm{e} 1}^{2}$ & $\sigma_{\mathrm{e} 2}^{2}$ & $\sigma_{\mathrm{e} 1 \mathrm{e} 2}$ & Correlação genética & \\
\hline${ }^{2} \mathrm{EGS}$ & AOL & 0,06 & 13,82 & 0,20 & 0,21 & 27,93 & 0,27 & $0,21 \pm 0,24$ & $0,11 \pm 0,09$ \\
\hline EGS & Peso & 0,06 & 291,82 & 2,44 & 0,21 & 982,93 & 1,46 & $0,57 \pm 0,23$ & $0,10 \pm 0,08$ \\
\hline${ }^{3} \mathrm{AOL}$ & Peso & 13,09 & 293,65 & 38,54 & 28,57 & 981,43 & 89,56 & $0,62 \pm 0,16$ & $0,53 \pm 0,06$ \\
\hline
\end{tabular}

EGS = espessura de gordura subcutânea; $\mathrm{AOL}=$ área de olho-de-lombo; $\sigma_{\mathrm{a} 1}{ }^{2} \mathrm{e}_{\mathrm{a} 2}{ }^{2}=$ variância aditiva direta das características 1 e 2, respectivamente; $\sigma_{\mathrm{a} 1 \mathrm{a} 2}=$ covariância aditiva direta entre as duas características; $\sigma_{\mathrm{e} 1}^{2}$ e $\sigma_{\mathrm{e} 2}{ }^{2}=$ variância residual das características 1 e 2, respectivamente; $\sigma_{\mathrm{e} 1 \mathrm{e} 2}=$ covariância residual entre as duas características.

\section{Conclusões}

Para rebanhos da raça Canchim, os efeitos de ano de nascimento, rebanho, sexo, grupo genético e idade devem ser incluídos no modelo de análise para estimar parâmetros genéticos para as características área de olho-de-lombo e espessura de gordura subcutânea. Essas características, mensuradas por ultrassom ao sobreano, devem responder à seleção nos rebanhos estudados. A seleção para peso ao sobreano deve resultar em mudanças correlacionadas na área de olho-de-lombo e na espessura de gordura subcutânea.

\section{Agradecimentos}

Às fazendas Água Marinha, Calabilu, Embrapa Pecuária Sudeste, Paraíso, Santana, Santa Helena e Vista Bonita, pela cessão dos dados.

Ao Dr. Flávio Shenckel, pelo auxílio nas análises.

\section{Referências}

ALENCAR, M.M.; BARBOSA, P.F.; BARBOSA, R.T. et al Parâmetros genéticos para peso e circunferência escrotal em touros da raça Canchim. Revista da Sociedade Brasileira de Zootecnia, v.22, n.4, p.572-583, 1993.

ARNOLD, J.W.; BERTRAND, J.K.; BENYSHEK, L.L. et al. Estimates of genetic parameters for live animal ultrasound, actual carcass data, and growth traits in beef cattle. Journal of Animal Science, v.69, p.985-992, 1991.

BOLDMAN, K.G.; KRIESE, L.A.; VAN VLECK, L.D. et al. A manual for use of MTDFREML. A set of programs to obtain estimates of variances and covariances [DRAFT]. Lincoln: Department of Agriculture, Agricultural Research Service, 1995. 120p.

BURROW, H.M.; GULBRANSEN, B.; JOHNSON, S.K. et al. Consequences of selection for growth and heat resistance on growth feed conversion efficiency commercial carcass traits and meat quality of Zebu crossbred cattle. Australian Journal Agriculture Research, v.42, p.1373-1383, 1991.

CREWS JR., D.H.; POLLAK, E.J.; WEABER, R.L. et al. Genetic parameters for carcass traits and their live animal indicators in Simmental cattle. Journal of Animal Science, v.81, p.1427-1433, 2003.

DAVIS, M.E.; BOYLES, S.L.; MOELLER, S.J. et al. Genetic parameter estimates for serum insulin-like growth factor-I concentration and ultrasound measurements of backfat 
thickness and longissimus muscle area in Angus beef cattle. Journal of Animal Science, v.81, p.2164-2170, 2003.

FERREIRA, J.J.; BRONDANI, I.L.; LEITE, D.T. et al. Características da carcaça de tourinhos Charolês e mestiços Charolês x Nelore terminados em confinamento. Ciência Rural, v.36, p.191-196, 2006.

HASSEN, A.; WILSON, D.E.; ROUSE, G.H. Evaluation of carcass, live, and real-time ultrasound measures in feedlot cattle: I. Assessment of sex and breed effects. Journal of Animal Science, v.76, p.273-282, 1998.

KEMP, D.J.; HERRING, W.O.; KAISER, C.J. Genetic and environmental parameters for steer ultrasound and carcass traits. Journal of Animal Science, v.80, p.1489-1496, 2002.

LAWRIE, R.A. Meat science. 50.ed. Oxford: Pergamon, 1991. 293p.

LIMA NETO, H.R.; BERGMANN, J.A.G.; GONÇALVES, T.M. et al. Estimativa de parâmetros genéticos para características de carcaça avaliadas por ultra-sonografia em bovinos da raça guzerá. Arquivo Brasileiro de Medicina Veterinária e Zootecnia, v.61, n.1, p.251-258, 2009.

LUCHIARI FILHO, A. Pecuária da carne bovina. São Paulo, 2000. 134p.

MAGNABOSCO, C.U.; ARAUJO, F.R.C.; MANICARDI, F. et al. Padrões de crescimento e características de carcaça de tourinhos nelore mocho, avaliados por ultra-sonografia em tempo real. In: REUNIÃO ANUAL DA SOCIEDADE BRASILEIRA DE ZOOTECNIA, 40., 2003, Santa Maria. Anais... Santa Maria: SBZ, 2003. (CD-ROM).

MASCIOLI, A.S.; ALENCAR, M.M.; BARBOSA, P.F. et al. Estimativas de parâmetros genéticos e proposição de critérios de seleção para pesos na raça Canchim. Revista Brasileira de Zootecnia, v.25, n.1, p.72-82, 1996.

MEYER, K.; JOHNTON, D.J.; GRASER, H.U. Estimates of the complete genetic covariance matrix for traits in multi-trait genetic evaluation of Australian Hereford cattle. Australian Journal of Agricultural Research, v.55, p.195-210, 2004.
MOSER, D.W.; BERTRAND, J.K.; MISZTAL, I. et al. Genetic parameters for carcass and yearling ultrasound measurements in Brangus cattle. Journal of Animal Science, v.76, p.2542-2548, 1998.

REVERTER, A.; JOHNSTON, D.J.; GRASER, H.U. et al. Genetic analyses of live animal ultrasound and abattoir carcass traits in Australian Angus and Hereford cattle. Journal of Animal Science, v.78, p.1786-1795, 2000.

RUBIANO, G.A.G.; ARRIGONI, M.B.; MARTINS, C.L. et al. Desempenho, características de carcaça e qualidade da carne de bovinos superprecoces das raças Canchim, Nelore e seus mestiços. Revista Brasileira de Zootecnia, v.38, n.12, p.2490-2498, 2009.

STELZLENI, A.M.; PERKINS, T.L.; BROWN JR., A.H. et al. Genetic parameter estimates of yearling live animal ultrasonic measurements in Brangus cattle. Journal of Animal Science, v.80, p.3150-3153, 2002.

TREMATORE, R.L.; ALENCAR, M.M.; BARBOSA, P.F. et al. Estimativas de efeitos aditivos e heteróticos para características de crescimento pré-desmama em bovinos Charolês - Nelore. Revista Brasileira de Zootecnia, v.27, n.1, p.87-94, 1998.

TURNER, J.W.; PELTON, L.S.; CROSS, H.R. Using live animal ultrasound measures of ribeye area and fat thickness in yearling Hereford bulls. Journal of Animal Science, v.68, p.3502-3506, 1990.

YOKOO, M.J.; AlBUQUERQUE, L.G.; LOBO, R.B. et al. Estimativas de parâmetros genéticos para altura do posterior, peso e circunferência escrotal em bovinos da raça Nelore. Revista Brasileira de Zootecnia, v.36, n.6, p.1761-1768, 2007.

YOKOO, M.J.; ALBUQUERQUE, L.G.; LOBO, R.B. et al. Genetic and environmental factors affecting ultrasound measures of longissimus muscle area and backfat thickness in Nelore cattle. Livestock Science, v.117, p.147-154, 2008.

YOKOO, M.J.; WERNECK, J.N.; PEREIRA, M.C. et al. Correlações genéticas entre escores visuais e características de carcaça 